\title{
Preliminary Dose Consequence Scoping Calculations for a Generic LWRHU Technology Platform
}

Greg A. Hula Noel R. Duckwitz

March 13, 2019

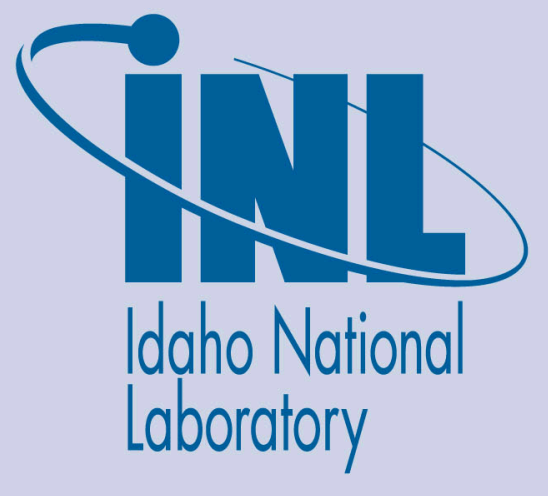

The INL is a U.S. Department of Energy National Laboratory operated by Battelle Energy Alliance 


\section{DISCLAIMER}

This information was prepared as an account of work sponsored by an agency of the U.S. Government. Neither the U.S. Government nor any agency thereof, nor any of their employees, makes any warranty, expressed or implied, or assumes any legal liability or responsibility for the accuracy, completeness, or usefulness, of any information, apparatus, product, or process disclosed, or represents that its use would not infringe privately owned rights. References herein to any specific commercial product, process, or service by trade name, trade mark, manufacturer, or otherwise, does not necessarily constitute or imply its endorsement, recommendation, or favoring by the U.S. Government or any agency thereof. The views and opinions of authors expressed herein do not necessarily state or reflect those of the U.S. Government or any agency thereof. 
INL/EXT-19-52889

Revision 1

\title{
Preliminary Dose Consequence Scoping Calculations for a Generic LWRHU Technology Platform
}

\author{
Greg A. Hula \\ Noel R. Duckwitz
}

March 13, 2019

\begin{abstract}
Idaho National Laboratory
Space Nuclear Power \& Isotope Technologies Division Idaho Falls, Idaho 83415
\end{abstract}

\section{http://www.inl.gov}

Prepared for the

U.S. Department of Energy

Office of Nuclear Energy

Under DOE Idaho Operations Office

Contract DE-AC07-05ID14517 

INTENTIONALLY BLANK 
Space Nuclear Power \& Isotope Technologies Division

\section{Preliminary Dose Consequence Scoping Calculations for a Generic LWRHU Technology Platform}

INL/EXT-19-52889

Revision 1

March 2019

Approved by:

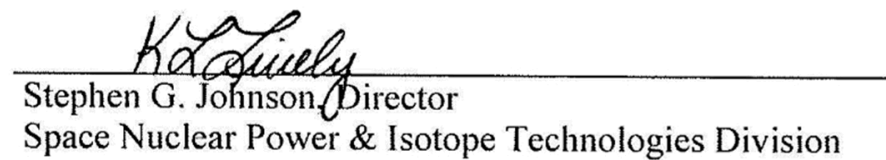

$\frac{3-13-19}{\text { Date }}$ 

INTENTIONALLY BLANK 


\section{CONTENTS}

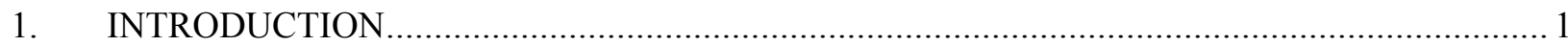

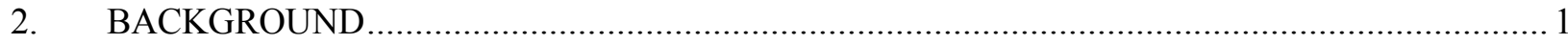

3. LIGHT-WEIGHT RADIOISOTOPE HEATER UNIT .................................................... 1

4. DOSE CONSEQUENCE SCOPING CALCULATION SUMMARY RESULTS ….....................2

4.1 Historical NASA Mission-Specific Risk Analyses Basis .................................................. 2

4.2 DOE Non-Reactor Nuclear Facility Safety Analysis Methodology ................................... 3

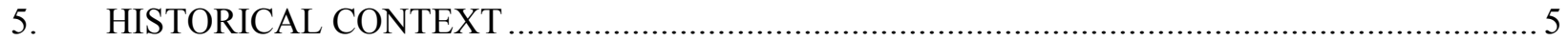

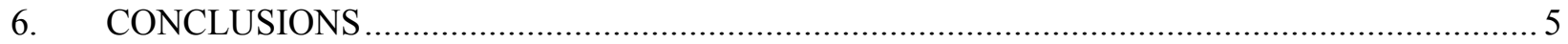

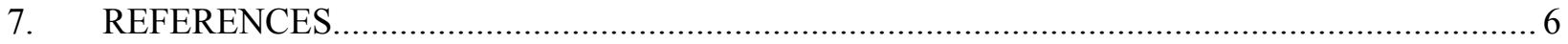


INTENTIONALLY BLANK 


\section{Preliminary Dose Consequence Scoping Calculations for a Generic LWRHU Technology Platform}

\section{INTRODUCTION}

The scoping calculations presented herein were developed to provide insight into a conservative, bounding estimate of radiological dose consequences associated with the use of Light-Weight Radioisotope Heater Units (LWRHUs) for potential NASA space missions. The dose consequence results may be used to support a National Aeronautics and Space Administration (NASA) Programmatic Environmental Assessment (PEA) of launches involving radioisotope heater units.

\section{BACKGROUND}

LWRHUs were developed by DOE to provide a means for maintaining acceptable operating temperatures for spacecraft and associated electronic equipment in applications where solar power is infeasible. LWRHUs have been used, or evaluated for use, in several NASA missions, including Galileo, Ulysses, Cassini, Mars Exploration Rovers, Pluto New Horizons, Mars Science Laboratory, and Mars 2020. These missions span a timeframe of 30 years.

When utilized, LWRHUs are typically located throughout a spacecraft to provide thermal heating to electronics and instrumentation. Spacecraft are launched into space using one of several different launch vehicles (e.g., Atlas V, Delta IV). The thrust necessary to propel a launch vehicle, with its spacecraft and nuclear payload, into space is provided by engines fueled by liquid and/or solid propellants. Pre-launch and launch-related accidents typically involve very energetic conditions including explosions (liquid propellant), fires (liquid or solid propellant), fragment impacts, and ground impacts.

NASA and DOE follow a rigorous process to quantify the risks associated with launch-related accidents, including Earth atmosphere reentry and post-reentry impacts. Mission-specific analyses include NEPA-related nuclear risk analyses (NRAs), launch-related safety analysis reports (SARs), and safety evaluation reports (SERs) issued by ad-hoc panels established to provide independent review and evaluation of the launch of nuclear power systems into space. These analyses quantify the risks (e.g., health effects, latent cancer fatalities) associated with the use of space nuclear power systems in the specific mission, including LWRHUs as applicable.

Reference 1 provides a comprehensive review and evaluation of the nuclear risk analyses and safety analyses developed to support past NASA missions that employed LWRHUs. The report provides summary information related to accident probabilities, consequences, and risk. These analyses typically present risk in the context of health effects (e.g., latent cancer fatalities), but often include missionspecific radiological dose consequences to a maximally exposed individual (MEI). While the analyses present a spectrum of results, the results have historically shown that the risk associated with LWRHUs is generally very small compared to that of other radioisotope power systems and is largely attributable to the robustness of the LWRHU design.

\section{LIGHT-WEIGHT RADIOISOTOPE HEATER UNIT}

The LWRHU is a radioisotope-fueled system consisting of a 1-W pellet of plutonium-238 dioxide $\left(\mathrm{PuO}_{2}\right)$, a clad of platinum-30 rhodium (Pt-30Rh), an insulation system of pyrolytic graphite, and an aeroshell/impact body of Fine-Weave Pierced Fabric. Nominal exterior dimensions are $26 \mathrm{~mm}$ (1 inch) diameter by $32 \mathrm{~mm}$ (1.25 inch) long. Each LWRHU weighs about $40 \mathrm{~g}$ and contains approximately $2.7 \mathrm{~g}$ $\mathrm{PuO}_{2}$. (ADD EIS NRA Reference here) 


\section{DOSE CONSEQUENCE SCOPING CALCULATION SUMMARY RESULTS}

Based on the extensive launch-related analyses that have been conducted for previous NASA missions in which LWRHUs were used, it is desirable to leverage this information to establish a bounding safety analysis against which future LWRHU-enabled missions can be evaluated. To that end, the results presented herein serve to provide a conservative estimate of dose consequences to the off-site public, consistent with previous mission-based risk and safety analyses. The results will provide further insight into the hazards associated with the use of LWRHUs and provide supporting information for use in future safety analysis development efforts.

In the interest of validation, two calculational methods are presented. Both methods are used to calculate dose consequences for an accident involving up to 130 LWRHUs. In addition, both methods account for the presence of the protective features of the LWRHU. Section 4.1 includes calculations based on per-Curie dose information developed from the Mars 2020 Environmental Impact Statement NRA and presented in Reference 1. Consistent with the nature of the EIS NRA methodology, this method implicitly accounts for the entire spectrum of launch-related accidents, including solid propellant fires. Section 4.2 presents calculations that use a methodology consistent with DOE-STD-3009-2014 ${ }^{2}$ and DOE-HDBK-3010, ${ }^{3}$ but account for the features of the LWRHU. The results are subsequently compared and discussed.

\subsection{Historical NASA Mission-Specific Risk Analyses Basis}

Reference 1, Section 2.7 therein, presents a comparison of per-curie dose consequences for an MMRTG, LWRHU and Curium-244 radioactive source based on the results of the Nuclear Risk Assessment (NRA) for the Mars 2020 Environmental Impact Statement. ${ }^{4}$ The NRA utilized a composite approach in calculating risks, which was based on a 50/50 weighting of the consequences for two launch vehicle configurations, an Atlas V 551 and a Delta IV Heavy. The following statement is excerpted from Section 2.7 of Reference 1: "Sufficient information exists to estimate the radiological consequences of radioactive materials without substantial confinement (such as radioactive sources used in spacecraft science instrumentation platforms) and those with substantial confinement (e.g., LWRHUs)." The percurie radiological dose consequence presented for a LWRHU level of protection, based on the "mean" dose consequences for the MEI in the NRA, is as follows:

- LWRHU protection: $<0.002 \mathrm{mrem} / \mathrm{Ci}$

- No protection: $<1 \mathrm{mrem} / \mathrm{Ci}$.

The EIS NRA identifies the radioactivity associated with each LWRHU to be approximately 33 curies. The radiological dose consequences based on the protective features of the LWRHU are calculated as follows:

Case 1 (80 LWRHUs): $0.002 \mathrm{mrem} / \mathrm{Ci} * 33 \mathrm{Ci} / \mathrm{LWRHU} * 80$ LWRHUs $=\mathbf{5 . 3}$ mrem (0.0053 rem)

Case 2: (130 LWRHUs): $0.002 \mathrm{mrem} / \mathrm{Ci} * 33 \mathrm{Ci} / \mathrm{LWRHU} * 130 \mathrm{LWRHUs}=\mathbf{8 . 6} \mathbf{~ m r e m}$ (0.0086 rem) 


\subsection{DOE Non-Reactor Nuclear Facility Safety Analysis Methodology}

This approach considers the launch vehicle, with its nuclear payload, in the context of a nuclear facility while it is present on the launch pad (i.e. before launch). The methodology uses the approach for calculating radiological doses for DOE non-reactor nuclear facilities and consists of two basic equations. The first equation establishes a source term based on the available total quantity of nuclear material present. The second equation uses the calculated source term to calculate a radiological dose consequence for a receptor located at a specified distance from the point of release. The source term is calculated as follows:

$\mathrm{ST}=\mathrm{MAR} * \mathrm{DR} * \mathrm{ARF} * \mathrm{RF} * \mathrm{LPF}$

where

ST: $\quad$ Source term, the amount of radioactive material, in grams or curies, driven airborne at the accident source that is effectively inhalable.

MAR: Material-at-risk, the amount of radionuclide material available to be acted on by a given stress.

DR: Damage ratio, the fraction of MAR actually acted upon by the accident-generated conditions.

ARF: Airborne release fraction, the coefficient used to estimate the amount of radioactive material suspended in air as an aerosol and thus available for transport due to physical stresses from a specific accident.

RF: Respirable fraction, the fraction of airborne radionuclides as particles that can be transported through the air into the human respiratory system.

LPF: Leak path factor, the fraction of radionuclides in the aerosol transported through some confinement deposition of filtration mechanism.

For purposes of this calculation and in accordance with DOE-HDBK-3010, the LPF is assumed to be 1.0. The values for the ARF and RF are accident-specific and are as follows. As discussed in Section 2, LWRHUs may be subjected to very energetic insults during launch-related accidents. These accidents generally involve launch vehicle failure that results in explosions/blasts, fires (liquid and/or solid propellants), and impacts. Based on review of previous mission-related launch safety analyses, solid propellant fuel fires generally bound all other insults due to their extremely high temperatures and energetic oxidation reaction. For example, solid propellant fuel fires may result in temperatures sufficient to vaporize the $\mathrm{PuO}_{2}$ fuel contained in a LWRHU if the solid propellant burns on, or in very close proximity to, the LWRHU.

For the damage ratio, the calculation presented herein takes into account the protective features of the LWRHU (i.e., Pt-30Rh clad and the protective graphite impact and insulator shells). While typically established through testing or analytical methods, the modified damage ratio takes into account the reported difference between the "per-Curie" dose presented for a level of protection afforded by the LWRHU $(<0.002 \mathrm{mrem} / \mathrm{Ci})$ versus an "unprotected" configuration $(<1 \mathrm{mrem} / \mathrm{Ci})$, as discussed in Reference 1 and summarized in Section 4.1 above. Based on these values, a damage ratio of 0.002 is used herein.

For purposes of establishing a conservative, bounding dose consequence estimate, DOE-HDBK-3010 was reviewed to identify accident insults that might provide a conservative approximation of a solid propellant fire directly affecting the ceramic plutonium oxide fuel. Section 4.2.1.1.4 therein provides bounding $\mathrm{ARF} / \mathrm{RF}$ values for thermal stresses that include oxidation events representative of very energetic surface reactions, such as bulk plutonium hydride oxidation in air. The oxidation reaction results in the conversion of plutonium hydride to plutonium oxide, which is then available for transport to a dose 
receptor. DOE-HDBK-3010 establishes a bounding ARF and RF of 1E-02 and 1.0, respectively, for oxidation events of this type. For purposes of this scoping calculation, the bounding ARF and RF for bulk plutonium hydride oxidation in air are used as an initial approximation to represent the vaporization of plutonium oxide fuel due to a solid propellant fire.

Based on the parameters discussed above the source term calculated for two different cases is as follows:

MAR $=(\#$ LWRHUs $) *(33$ Ci/LWRHU $)$

$\mathrm{DR}=0.002$

$\mathrm{ARF}=1 \mathrm{E}-02$

$\mathrm{RF}=1.0$

$\mathrm{LPF}=1.0$

Case 1 (80 LWRHUs): $\mathrm{ST}=0.053 \mathrm{Ci}$

Case 2 (130 LWRHUs): ST $=0.086 \mathrm{Ci}$.

The second formula uses the calculated source term to calculate a radiological dose, as follows: $\mathrm{CED}=\mathrm{ST} * \mathrm{X} / \mathrm{Q} * \mathrm{BR} * \mathrm{DCF}$

where

CED: Committed effective dose, represents the 50-year effective dose from inhalation of radionuclides. Use of CED neglects the contribution of total dose from direct shine and cloud shine, which is typically very small relative to the dose received from inhalation.

ST: $\quad$ Source term (discussed above)

X/Q: Dispersion coefficient, the factor that accounts for dispersion of the respirable radioactive material from the point of release to the dose receptor location. The INL-developed Radiological Safety Analysis Computer (RSAC) program ${ }^{a}$ was used to calculate an initial dispersion coefficient for a ground-level release at a distance of $16 \mathrm{~km}$ (10 miles) from the launch site. The calculation conservatively used a Pasquill Gaussian dispersion model with stability class $\mathrm{F}$ and wind speed of $1 \mathrm{~m} / \mathrm{s}$ (95\% confidence levels), both of which are default parameters per DOE-STD-3009-2014, which resulted in a value of $1.24 \mathrm{E}-05 \mathrm{~s} / \mathrm{m}^{3}$.

BR: $\quad$ Breathing rate, represents the amount of air breathed by an adult. In accordance with DOE-STD-3009-2014, the default value of $3.3 \mathrm{E}-04 \mathrm{~m}^{3} / \mathrm{s}$ is used.

DCF: Dose conversion factor, the factor that converts the amount of radioactivity deposited in the body through inhalation. Dose consequence is estimated based on the dose conversion factor (DCF) for the off-site public selected from the International Commission on Radiation Publication 72 (ICRP-72), "Age-Dependent Doses to Members of the Public from Intake of Radionuclides." The ICRP-72 methodology results in a 50-year committed effective dose (CED) determination for inhaled radionuclides. If pathways other than internal are added to the CED, then the result is the total effective dose (TED). Because of the dominance of the inhalation dose, the CED results are roughly equivalent to the TED determination. The DCF value selected for use in this calculation was $4.0 \mathrm{E}+08$ rem/Ci (for Pu-238 oxide), based on similar safety analyses.

a. The RSAC computer code is currently maintained by ORNL but is not currently listed as a "tool-box" code. 
Based on the equation and factors discussed above, mitigated dose consequences for the off-site public (i.e., a hypothetical dose receptor located 10 miles from the launch complex) are calculated as follows:

$\mathrm{CED}=\mathrm{ST} * \mathrm{X} / \mathrm{Q} * \mathrm{BR} * \mathrm{DCF}$

Case $1\left(80\right.$ LWRHUs): $5.3 \mathrm{E}-02 \mathrm{Ci} *\left(1.24 \mathrm{E}-05 \mathrm{~s} / \mathrm{m}^{3}\right) *\left(3.3 \mathrm{E}-04 \mathrm{~m}^{3} / \mathrm{s}\right) *(4.0 \mathrm{E}+08 \mathrm{rem} / \mathrm{Ci})=$ 0.086 rem (86 mrem)

Case 2 (130 LWRHUs): $8.6 \mathrm{E}-02 \mathrm{Ci} *\left(1.24 \mathrm{E}-05 \mathrm{~s} / \mathrm{m}^{3}\right) *\left(3.3 \mathrm{E}-04 \mathrm{~m}^{3} / \mathrm{s}\right) *(4.0 \mathrm{E}+08 \mathrm{rem} / \mathrm{Ci})=$ 0.140 rem (140 mrem).

\section{HISTORICAL CONTEXT}

Table 1 presents the "mean" MEI radiological dose consequences presented in the Final Safety Analysis Report for the 2003 Mars Exploration Rover (MER) mission. ${ }^{5}$ Each MER was assumed to hold 10 LWRHUs. The MERs were launched aboard Delta II launch vehicles form Launch Complex 17 at Cape Canaveral Air Force Station. The dose consequences are scaled to reflect 80 and 130 LWRHUs, to provide further comparison with the dose consequences presented in Section 4.

Table 1. MER Maximum Individual Radiological Dose Consequences (2003).

\begin{tabular}{|l|c|c|}
\hline \multirow{2}{*}{} & \multicolumn{2}{|c|}{ Maximum Individual Dose, rem (mrem) ${ }^{\mathrm{a}}$} \\
\cline { 2 - 3 } & MER-A & MER-B \\
\hline Mean (10 LWRHUs) & 3.59E-02 (36) & $6.73 \mathrm{E}-03(7)$ \\
\hline 80 LWRHUs (scaled) & $2.87 \mathrm{E}-01(287)$ & $5.38 \mathrm{E}-02(54)$ \\
\hline 130 LWRHUs (scaled) & 4.67E-01 (467) & $8.75 \mathrm{E}-02(88)$ \\
\hline $\begin{array}{l}\text { a. The dose consequences include the contribution from non-LWRHU radioisotopes present in scientific } \\
\text { instrumentation on the spacecraft and rover. As such, the dose contribution due to Pu-238 would be lower } \\
\text { than those shown. }\end{array}$
\end{tabular}

\section{CONCLUSIONS}

The following observations and conclusions are made relative to the dose consequence calculations presented in Section 4 and the scaled MER dose consequences presented in Section 5:

1. In all cases, the calculated dose consequences are well below the 25 Rem evaluation guideline (EG) for an extremely unlikely event for consequences to the off-site public as specified in DOE-STD3009-2014, thereby demonstrating the significant benefit of the protective features of the LWRHU. ${ }^{\mathrm{b}}$ Further, the calculated dose consequences are below the 5 Rem EG for an unlikely event for consequences to the off-site public.

2. The passive design features and robustness of the LWRHU design would serve to minimize radiological dose to the off-site public and demonstrate a robustness commensurate with a safetyclass SSC designation.

b. Per DOE-STD-3009-2014, the 25 rem Evaluation Guideline is not a safety standard because it does not define an acceptable or unacceptable dose from an accident. Rather, it is a criterion used by DOE to help identify or define what measures and controls are necessary to ensure adequate protection of the off-site public. 


\section{REFERENCES}

1. "Review of Requirements for NASA Radioisotope Power System Enabled Missions and Lessons Learned from the Review of Mission Safety Analysis, A Review of NASA NEPA and Safety Requirements with Lessons Learned from Previous Safety Analyses," Daniel W. Gallagher and Douglas A. Outlaw, Leidos Inc., July 2017.

2. DOE-STD-3009-2014, "Preparation of Nonreactor Nuclear Facility Documented Safety Analysis," December 2014.

3. DOE-HDBK-3010-94, "Airborne Release Fractions/Rates and Respirable Fractions for Nonreactor Nuclear Facilities," Volume 1 - Analysis of Experimental Data, December 1994.

4. "Nuclear Risk Assessment for the Mars 2020 Mission Environmental Impact Statement," SAND2013-10589, January 2014.

5. "Light Weight Radioisotope Heater Unit Final Safety Analysis Report for the Mars Exploration Rover - 2003 Project," TtNUS-02-0018A, October 30, 2002. 